\title{
Zeytinlerde potansiyel tehlike: Philaenus spumarius (Linnaeus) (Cercopidae) ve Auchenorrhyncha türleri (Hemiptera) ${ }^{1}$
}

\author{
$\underline{\text { Gülay KACAR }}{ }^{2}$ Hüseyin BAŞPINAR ${ }^{3}$
}

Ünal ZEYBEKOĞLU ${ }^{4}$

\author{
M. Rifat ULUSOY ${ }^{5}$
}

\begin{abstract}
Potential treat for olives: Philaenus spumarius (Linnaeus) (Cercopidae) and Auchenorrhyncha species (Hemiptera)
\end{abstract}

Philaenus spumarius (Linnaeus) (Hemiptera: Auchenorrhyncha: Cercopidae) is an important vector pest to transmit Xylella fastidiosa bacterium. In addition to that species, some species of Cicadellidae, Cercopidae, Cicadidae and Dictyopharidae (Auchenorrhyncha) are vector of $X$. fastidiosa bacterium. X. fastidiosa effects the plants show drying, scorching, and wilting of the foliage, dieback eventually followed by sudden plant death. The members of Cicadoidea and Fulgoroidea (Auchenorrhyncha) superfamilies feed the suck saps of grass, shrubs and trees. Besides, some of species encompass economically important pests as some of them virus, phytoplasmas and bacterium vectors. This study was conducted to determine the species of Auchenorrhyncha species in olive groves in Adana, Hatay, Mersin, Osmaniye, Kahramanmaraş, Gaziantep and Kilis provinces in Turkey between 2008 and 2013. Samples were collected from at least $0.01 \%$ trees from each province. Trees $5 \%$ of each grove were sampled randomly from their four cardinal directions, which insects were collected by shaking and knocking the branch three times a $1 \mathrm{~m}^{2}$-section of tree foliage into Steiner funnel shaped collector, monitoring method and a hand aspirator from olive twigs. Collected species were separated, killed and pinned in the laboratory afterwards. In total, 30 species from four families such as Cicadellidae (22), Cercopidae (4), Dictyopharidae (2) and Cixidae (2)

\footnotetext{
${ }^{1}$ Türkiye VI. Bitki Koruma Kongresi, Konya'da özet olarak sunulmuştur.

${ }^{2}$ Abant İzzet Baysal Üniversitesi, Ziraat ve Doğa Bilimleri Fakültesi, Bitki Koruma Bölümü, 14030, Gölköy, Bolu

${ }^{3}$ Adnan Menderes Üniversitesi, Ziraat Fakültesi, Bitki Koruma Bölümü, 09970, Koçarlı, Aydın

${ }^{4}$ Ondokuzmayıs Üniversitesi, Fen Edebiyat Fakültesi, Biyoloji Bölümü, 55105, Atakum, Samsun

${ }^{5}$ Çukurova Üniversitesi, Ziraat Fakültesi, Bitki Koruma Bölümü, 01330, Sarıçam, Adana

Sorumlu yazar (Corresponding author) e-mail: gulaysahan@ @ahoo.mail

Alınış (Received): 16.08.2017, Kabul ediliş (Accepted): 26.12.2017
} 
Zeytinlerde potansiyel tehlike: Philaenus spumarius (Linnaeus) (Cercopidae) ve Auchenorrhyncha türleri (Hemiptera)

families were identified. P. spumarius, Docotettix cornutus Ribaut, Empoasca sp. and Asymmetrasca decedens (Paoli) (Cicadellidae) were found to be the most common species in olive groves, but it wasn't determined their economic damage.

Keywords: Philaenus spumarius, Xylella fastidiosa, Auchenorrhyncha, olive

\section{ÖZ}

Philaenus spumarius (Linnaeus) (Hemiptera: Auchenorrhyncha: Cercopidae), zeytinlerde hastalık oluşturan Xylella fastidiosa bakterisini taşıyan önemli bir vektördür. Bu türün yanı sira Cicadellidae, Cercopidae, Cicadidae ve Dictyopharidae (Auchenorrhyncha) familyasina bağlı bazı böcek türlerinin de $X$. fastidiosa bakterisine vektörlük yaptığı bilinmektedir. $X$. fastidiosa, zeytinlerde hastalanmış ağaçların yapraklarında yanıklık, sürgünlerde ve dallarda geriye doğru ölüm meydana getirerek ani ölümlerine neden olur. Cicadoidea ve Fulgoroidea (Auchenorrhyncha) üst familyaları ağaçlar, çalımsı ve otsu bitkilerin özsuyunu emerek beslenirler. Ayrıca bazı türleri virüs, fitoplazma ve bakteri gibi hastalık etmenlerinin vektörlüğünü yaparak da ekonomik açıdan önemli zarara neden olurlar. Bu çalışma Adana, Hatay, Mersin, Osmaniye, Kahramanmaraş, Gaziantep ve Kilis ili zeytin bahçelerinde 20082011 yılları arasında Auchenorrhyncha türlerini belirlemek amacıyla yürütülmüştür. Örnekler her ilin zeytin ağaç varlığının en az \%0.01'den toplanmıştır. Her bahçede bulunan ağaç sayısının \% 5 'inden örnekleme gerçekleştirilmiştir. Tesadüfen seçilen her bir ağacın dört yönünden rastgele bir dalına üç defa vurularak Steiner hunisi, ağız aspiratörü ve gözle kontrol yöntemiyle sürgünlerde ve meyvelerde belirlenen örnekler toplanmıştır. Daha sonra laboratuvara getirilen örnekler usulüne uygun olarak teşhise hazır hale getirilmiştir. Çalışma sonucunda, Cicadellidae (22), Cercopidae (4), Dictyopharidae (2) ve Cixiidae (2)'de olmak üzere dört familyadan toplam 30 tür belirlenmiştir. Bu türler içerisinde $P$. spumarius (Cercopidae), Docotettix cornutus Ribaut, Empoasca sp. ve Asymmetrasca decedens (Paoli) (Cicadellidae) zeytin bahçelerinde en yaygın görülen türlerdir. Ancak söz konusu türlerin ekonomik anlamda zararı tespit edilmemiştir.

Anahtar kelimeler: Philaenus spumarius, Xylella fastidiosa, Auchenorrhyncha, zeytin

\section{GíRiş}

Zeytin, Akdeniz iklimine sahip alanlarda doğal olarak yetişebilen bir ağaçtır. Türkiye, zeytin yetiștirilen alan ve ağaç varlığı bakımından Dünya'da dördüncü sirada, sofralık zeytin üretiminde ise ikinci sirada yer almaktadır (Anonymous 2015a). Zeytin yetiştiriciliği daha çok Ege ve Marmara Bölgelerinde yoğunlaşmakla birlikte Akdeniz, Karadeniz ve Güneydoğu Anadolu Bölgelerinin bazı yörelerinde de yapılmaktadır (Anonim 2016). Zeytin, besin değeri yüksek olduğu için insan sağlığı açısından önemli bir gıda maddesi olmasının yanı sıra, ülke ekonomisi ve halkın beslenmesi açısından da önemli bir kültür bitkisidir (Pala ve ark. 2001).

Cicadoidea ve Fulgoroidea (Hemiptera: Auchenorrhyncha) üst familyalarına bağlı böceklerin tamamı fitofag olup, bunlar Ağustos böcekleri, Yaprak pireleri ve Tükrük böcekleri olarak bilinen türleri içermektedir. Bu gruba bağlı böcek türleri ağaçlar, çalımsı ve otsu bitkilerde emgi yaparak beslenirler, ancak bu türlerin çok azı 
ekonomik önemde zararlılar konumundadır. Özellikle Cicadellidae familyasına bağlı bazı türler gerek bitkilerde beslenme zararı ve gerekse virüs, fitoplazma ve bakteri gibi hastalık etmenlerinin vektörlügünü yaparak ekonomik zarara neden olmaktadır. Cicadellidlerin Stubborn, Misır chloratic-dwarf, Çeltik tungro ve Çeltik tungro-like gibi önemli virüs hastalıklarının taşıyıcısı olduğu kaydedilmiştir (Başpınar ve Uygun 1994, Harris 1981, 1983, Nault 1986). Amerika ve İtalya'da yapılan çalışmalarda; Auchenorrhyncha (Hemiptera)'dan Aphrophoridae, Cicadellidae, Cicadidae ve Cercopidae'dan çok sayıda türün Xylella fastidiosa bakterisinin vektörü olduğu bildirilmiştir (Anonymous 2016a, Saponari et al. 2014). İtalya'da Philaenus spumarius (Linnaeus) (Cercopidae)'un zeytin bahçelerinde yaygın bir tür olduğu ve $X$. fastidiosa bakterisini taşıyan önemli bir vektör böcek olduğu belirlenmiştir (Saponari et al. 2014). Kuzey Amerika, Yeni Zelanda, Hawaii ve Avrupa'da $P$. spumarius'un yabancı otlardan, bahçe bitkilerine ve ağaçlara kadar çok sayıda konukçusu (Alnus, Casuarina, Ceanothus, Comptonia, Elaeagnus ve Myrica vs.) olduğu kaydedilmiştir (Archibald and Cox 1979, Booth 1993, Thompson 1998, Weaver and King 1954, Yurtsever 2000).

$X$. fastidiosa ise 200 'den fazla konukçuya sahip olup; turunçgiller, zeytin, asma, şeftali, erik, kayısı, karaağaç, çınar, meşe, akçaağaç ve yonca gibi ekonomik öneme sahip bitki türlerinde büyük kayıplara neden olmaktadır (Anonymous 2016a, Aysan 2016). Bu bakterinin konukçuları arasında bulunan zeytin ağaçlarında İtalya' da ciddi zarara neden olduğu kaydedilmiştir (Anonymous 2016a). Bu bakterinin zeytin ağaçlarında çok yoğun yaprak yanıklı̆̆ 1 ve sürgün, dal ve ağacın tamamında geriye doğru kuruma sonucu ani ölümlere neden olduğu kayıtlarda bildirilmiştir (Anonymous 2016a, Aysan 2016). Ülkemiz karantina listesinde yer alan $X$. fastidiosa, Şanlıurfa'da badem ağaçlarında varlı̆̆ 1 ilk defa bildirilmekle birlikte, etmenin tespitinde sadece ELISA ve elektron mikroskopi görüntüleri kullanıldığından varlığı tam olarak açıklığa kavuşmamış ve teyit edilmemiş kayıt olarak kalmıştır (Anonymous 2015b, Anonymous 2016b, Guldur et al. 2005).

$X$. fastidiosa bakterisinin çok sayıda konukçusu olması ve vektör böcekler ile taşınabilmesi nedeniyle, ülkemiz meyveciliği açısından potansiyel bir tehlike konumundadır. Bu bakterinin vektörleri arasında bulunan Auchenorrhyncha böcek türlerinin belirlenmesi, hastalığın potansiyel ilerleme senaryosunu saptamada önemli bir yer tutacaktır. Bu nedenle ele alınan bu çalışmada Adana, Hatay, Mersin, Osmaniye, Kahramanmaraş, Gaziantep ve Kilis ili zeytin bahçelerinde Cicadellidae, Cercopidae, Cixiidae ve Dictyopharidae türleri ile yayılış alanları belirlenmiş ve $X$. fastidiosa bakterisinin en önemli taşıyıcısı olan Philaenus spumarius'un bulunduğu yerler ortaya çıkarılmıştır.

\section{MATERYAL VE METOT}

Bu çalışma, Akdeniz Bölgesinde zeytin alanlarında Auchenorrhyncha türlerini ve yayılış alanlarını belirlemek amacıyla Adana (Aladağ, Ceyhan, İmamoğlu, Karaisalı, Karataş, Kozan, Sarıçam, Seyhan, Yüreğir, Yumurtalık), Gaziantep (Araban, 
Zeytinlerde potansiyel tehlike: Philaenus spumarius (Linnaeus) (Cercopidae) ve Auchenorrhyncha türleri (Hemiptera)

İslahiye, Nizip, Nurdağı, Oğuzeli, Şahinbey, Şehitkamil), Hatay (Altınözü, Belen, Dörtyol, Erzin, Hassa, İskenderun, Kırıkhan, Kumlu, Reyhanlı, Samandağ, Yayladăğ1), Mersin (Akdeniz, Anamur, Aydıncık, Bozyazı, Gülnar, Erdemli, Mut, Tarsus, Taşucu, Toroslar, Mezitli, Silifke), Osmaniye (Bahçe, Düziçi, Hasanbeyli, Kadirli, Sumbas, Toprakkale), Kahramanmaraş (Andırın, Merkez, Pazarcık, Türkoğlu) ve Kilis (Elbeyli, Musabeyli, Polateli, Merkez) illerinin yoğun zeytin yetiștiriciliği yapılan ilçelerinde 2008-2013 yılları arasında yürütülmüștür. Arazi çıkışları periyodik olmayan çıkışlar şeklinde, ancak her ay her il ve ilçelerine gidilecek şekilde yapılmıştır. Örneklemeler il ve ilçelerin zeytin ağaç sayılarının en az \%0.01'de gerçekleştirilmiştir. Toplam 760 bahçede örnekleme yapılmıştır. Örnekler her bir zeytin bahçesinde bulunan ağaç sayısının en az \%5'inden gerçekleştirilmiştir. Tesadüfen seçilen her bir ağacın dört yönünden rastgele bir dalına üç defa vurularak $1 \mathrm{~m}^{2}$ lik Steiner hunisi, ağız aspiratörü ve gözle kontrol yöntemi ile yaprak ve sürgün örnekleri alınarak uygun bir şekilde toplanmıştır. Daha sonra laboratuvara getirilen örnekler öldürme şişesinde öldürüldükten sonra, ergin bireyler stereo-binoküler mikroskop ile diğer böcek ve bitki parçalarından ayrılarak, usulüne uygun olarak teşhise hazır hale getirilmiş ve konu uzmanına gönderilmiştir.

\section{SONUÇLAR}

Akdeniz Bölgesi zeytin alanlarında Cicadellidae (22), Cercopidae (4), Cixiidae (2) ve Dictyopharidae (2)'de olmak üzere dört familyadan toplam 30 tür belirlenmiştir (Çizelge 1). Bu türler içinde Philaenus spumarius (Linnaeus) (Cercopidae), Docotettix cornutus Ribaut, Empoasca sp. ve Asymetresca decedens (Paoli) (Cicadellidae) zeytin bahçelerinde en yaygın görülen türler olmuş, ancak söz konusu türlerin ekonomik anlamda zararı saptanmamıştır. Çalışma sonucu belirlenen türler ocak ayından aralık ayına kadar tüm yıl boyunca belirlenmiştir (Çizelge 1). Ancak Cicadellidae türleri (Empoasca sp. ocak ve şubat, A. decedens ve Zyginella sp. şubat ve $D$. cornutus mart aylarında) kış aylarında zeytinler üzerinden toplanmasına karşın, Cercopidae, Cixiidae ve Dictypharidae türleri ilkbahardan yıl sonuna kadar elde edilmiştir. Çizelge 1 incelendiğinde Akdeniz ikliminin tam olarak hakim olduğu Adana, Osmaniye ve Mersin'den karasal iklime doğru gidilen iç kesimlere kadar farklı ekolojik koşullarda Cicadellid tür zenginliği ortaya çıkmaktadır.

Çizelge 1. Akdeniz Bölgesi zeytin bahçelerinde Auchenorrhyncha (Hemiptera)'ya bağlı türler, yayılışı ve bulunduğu aylar

\begin{tabular}{|l|l|l|l|}
\hline Familya & Tür & Bulunduğu yer & Bulunduğu ay \\
\hline \multirow{3}{*}{ Cicadellidae } & Allygus sp. & Hatay (Merkez), Altınözü & IV \\
\cline { 2 - 4 } & $\begin{array}{l}\text { Anaceratagallia sinuata } \\
\text { (Mulsant Et Ray) }\end{array}$ & Şehitkamil & XII \\
\hline
\end{tabular}


Çizelge 1. (Devamı)

\begin{tabular}{|c|c|c|c|}
\hline Familya & Tür & Bulunduğu yer & Bulunduğu ay \\
\hline \multirow{20}{*}{ Cicadellidae } & $\begin{array}{l}\text { Anaceratagallia ribauti } \\
\text { (Ossiannilson) }\end{array}$ & Dörtyol & $\mathrm{V}$ \\
\hline & $\begin{array}{l}\text { Arboridia adanae } \\
\text { (Dlabola) }\end{array}$ & Nizip, Kozan & $\mathrm{XI}$ \\
\hline & Artianus sp. & Pazarcık & $\mathrm{V}$ \\
\hline & $\begin{array}{l}\text { Asymmetrasca decedens } \\
\text { (Paoli) }\end{array}$ & $\begin{array}{l}\text { Erzin, Hassa, Musabeyli, } \\
\text { Nizip, Oğuzeli, Şahinbey, } \\
\text { Sehitkamil }\end{array}$ & II, XII, XI, \\
\hline & $\begin{array}{l}\text { Cicadulina bipunctella } \\
\text { (Matsumura) }\end{array}$ & Erzin, Kilis (Merkez) & $\mathrm{XI}$ \\
\hline & $\begin{array}{l}\text { Circulifer haemotoceps } \\
\text { (Mulsantand and Rey) }\end{array}$ & Şahinbey & $\mathrm{XI}$ \\
\hline & $\begin{array}{l}\text { Docotettix cornutus } \\
\text { Ribaut }\end{array}$ & $\begin{array}{l}\text { Belen, Dörtyol, Hassa, } \\
\text { İskenderun, Kırıkhan, } \\
\text { Musabeyli, Tarsus, } \\
\text { Sarıçam, Yüreğir, } \\
\text { Toprakkale }\end{array}$ & $\begin{array}{l}\text { III, IV, V, } \\
\text { VIII, IX, X, } \\
\text { XI, XII }\end{array}$ \\
\hline & Empoasca sp. & $\begin{array}{l}\text { Erzin, Hassa, Kadirli, } \\
\text { Musabeyli, Nizip, } \\
\text { Polateli, Sarıcam, } \\
\text { Şahinbey, Şehitkamil, } \\
\text { Tarsus, Türkoğlu, } \\
\text { Yüreğir }\end{array}$ & $\begin{array}{l}\text { I, II, IV, XI, } \\
\text { XII, }\end{array}$ \\
\hline & Empoasca solani (Curt.) & Nizip & $\mathrm{XI}$ \\
\hline & $\begin{array}{l}\begin{array}{l}\text { Empoasca decipiens } \\
\text { (Paoli) }\end{array} \\
\end{array}$ & Nizip & $\mathrm{XI}$ \\
\hline & Fieberiella sp. & Şehitkamil & XII \\
\hline & $\begin{array}{l}\text { Frutioidia bisignata } \\
\text { (Mulsant Et Ray) }\end{array}$ & Islahiye & XI \\
\hline & $\begin{array}{l}\text { Megophthalmus } \\
\text { scabripennisEdwards }\end{array}$ & Ceyhan, Karaisalı & $\mathrm{V}, \mathrm{XI}$ \\
\hline & $\begin{array}{l}\text { Thamnotettix zelleri } \\
\text { Kirschbaum }\end{array}$ & Kozan & VI \\
\hline & Thamnotettix sp. & Kozan & VI \\
\hline & Synophoropsis sp. & Andırın & $\mathrm{X}$ \\
\hline & $\begin{array}{l}\text { Psammotettix cerinus } \\
\text { Lindberg }\end{array}$ & Kadirli & XII \\
\hline & $\begin{array}{l}\text { Psammotettix provincialis } \\
\text { (Ribaut) }\end{array}$ & Oğuzeli & VI \\
\hline & Zyginella sp. & Sarıçam & II \\
\hline & Zyginidia pullula Fieber & $\begin{array}{l}\text { Dörtyol, Erzin, Kozan, } \\
\text { Pazarcık }\end{array}$ & $\mathrm{V}, \mathrm{XI}$ \\
\hline
\end{tabular}


Zeytinlerde potansiyel tehlike: Philaenus spumarius (Linnaeus) (Cercopidae) ve Auchenorrhyncha türleri (Hemiptera)

Çizelge 1. (Devamı)

\begin{tabular}{|l|l|l|l|}
\hline Familya & Tür & Bulunduğu yer & Bulunduğu ay \\
\hline \multirow{5}{*}{ Cercopidae } & $\begin{array}{l}\text { Triecphorella } \\
\text { geniculata } \text { (Horvath) }\end{array}$ & Toprakkale & IV \\
\cline { 2 - 4 } & Philaenus spumarius L. & $\begin{array}{l}\text { Erzin, Kadirli, Kozan, } \\
\text { Tarsus, Yüreğir }\end{array}$ & IV, XI, X \\
\cline { 2 - 4 } & $\begin{array}{l}\text { Lepyronia coleoptrata } \\
\text { L. }\end{array}$ & Sarıçam & VI \\
\cline { 2 - 4 } Cixiidae & $\begin{array}{l}\text { Neophilaenus } \\
\text { campestris } \text { (Fallen) }\end{array}$ & Osmaniye (Merkez) & X \\
\hline & $\begin{array}{l}\text { Pentastira rorida } \\
\text { Fieber }\end{array}$ & Şahinbey & VII \\
\cline { 2 - 4 } Dictyopharidae & $\begin{array}{l}\text { Cixius simplex } \\
\text { (Herrich-Schaffer) }\end{array}$ & Dörtyol & XI \\
\cline { 2 - 4 } & $\begin{array}{l}\text { Ditcyophara europaea } \\
\text { L. }\end{array}$ & Tarsus & VIII \\
Dictyophara pannonica & Hasanbeyli & VIII \\
\hline
\end{tabular}

\section{TARTIŞMA VE KANI}

Çalışmamızda, ayrıca zeytin bahçelerinde P. spumarius, A. decedens (Paoli), D. cornutus ve Empoasca sp. (Cicadellidae) türleri de yaygın olarak bulunmuştur (Çizelge 1). Bölgede zeytin bahçelerinde yapılan sınırlı sayıda çalışmada, Antalya ilinde Cixidae familyasından Reptalus (Oliarus) melanochaetus Fieber (Yayla 1983), Güneydoğu Anadolu Bölgesi zeytinliklerinde (Adıyaman, Gaziantep, Mardin ve Şanlıurfa) Empoasca sp., Circulifer haematoceps (Mulsant and Rey) ve Zyginella ulchra Low (Cicadellidae) (Kaplan ve ark. 2011) türlerinin varlığı bildirilmiştir. Ayrıca, bu bölgede meyve bahçelerinde yapılan diğer çalışmalarda A. decedens ve E. decipiens Paoli, nar ve antepfistığı zararlısı olarak kaydedilmiştir (Bolu 2002, Öztürk ve ark. 2005).

P. spumarius, yedi farklı zeytin bahçesinden toplanmıştır. P. spumaris'in Kadirli (Osmaniye), Tarsus (Mersin), Sarıçam ve Kozan (Adana), Erzin (Hatay)'da yayılış gösterdiği belirlenmiştir. Bu zararlının erginleri zeytinlerden nisan, ekim ve kasım aylarında toplanmıştır. $P$. spumarius hem doğrudan bitki özsuyunu emerek ve hem de bazı bitki hastalıklarını taşıyarak zararlı olmaktadır (Yurtsever 1999). Çok sayıda konukçusu olan $P$. spumarius'un çok sayıda konukçuda çayır bitkileri, otlar, dikenler, bahçe bitkileri, çalılıklar, hatta kozalaklılarda dâhil olmak üzere, otlardan ağaçlara kadar birçok farklı türden bitkide beslendiği bildirilmiştir (Archibald and Cox 1979, Booth 1993, Weaver and King 1954, Yurtsever 1999). İtalya'da hastalanmış zeytin ağaçlarında $X$. fastidiosa'nın yanı sıra, Phaeoacremonium spp., Phaemoniella spp. fungus türleri ile Zeuzera pyrina L. (Lepidoptera: Cossidae) zararlısının bu hastalıkla bağlantılı olduğu kaydedilmiştir (Anonymous 2016a). Zeytin ağaçlarında $P$. spumarius'u değerlendirirken, bu hastalık etmeni ile $Z$. pyrina 
zararını göz önünde tutmak gerekmektedir. İtalya'da yapılan bir çalışmada zeytin bahçelerinde yaygın bir tür olan $P$. spumarius'un, $X$. fastidiosa bakterisini taşıdığı, ayrıca bu bakterinin vektörleri arasında Cicadidae, Aphrophoridae, Cercopidae ve Cicadellidae türlerinin de olabileceği bildirilmiştir (Saponari et al. 2014). Yine aynı ülkede yapılan diğer bir çalışmada $X$. fastidiosa ile enfekteli zeytin bahçelerinden toplanan $P$. spumarius örneklerinin PCR sonucunda \%67'sinin pozitif olarak hastalığ bünyelerinde barındırdığı belirlenmiştir (Saponari et al. 2014). Kaliforniya (ABD) eyaletinde zeytin bahçelerinde $X$. fastidiosa'nın altı ırk1 saptanmış, zeytindeki ırkı $X$. fastidiosa subsp. multiplex olarak tanımlanmıştır (Krugner et al. 2014). Saponari et al. (2016) tarafından İtalya'da yapılan çalışma sonucunda zeytinlerdeki ırkın $X$. fastidiosa subsp. pauca olduğu belirlenmiş ve patojenisite ile de teyit edilmiştir. $\quad X$. fastidiosa subsp. fastidiosa streyninin asmada Pierce hastalığına neden olduğu, bademinde içinde yer aldığı diğer konukçuları da hastalandırdığ 1 belirlenmiştir (Chen et al. 2005, Davis et al. 1978). Amerika'da yapılan diğer bir çalışmada da X. fastidiosa vektörleri olarak; Graphocephala atropunctata Signoret, Draeculacephala minerva Ball, Xyphon (Carneocephala) fulgida Nottingham, Acrogonia terminalis Young, Dilobopterus costalimai Young ve Oncometopia fascialis Signoret (Cercopidae) türlerini bildirmişlerdir (Anonymous 2016a, Daane et al. 2011, Purcell and Saunders 1999, Sisterson et al. 2010).

$X$. fastidiosa bakterisinin zeytinlerin hılı bir şekilde ölümüne neden olduğu, hastalanmış ağaçlarda yapraklarda yanıklık, sürgünlerde, dallarda geriye doğru ani ölüm meydana getirdiği bildirilmiştir (Anonymous 2016a). Ülkemizde Güldür et al. (2005) tarafından yürütülen çalışmada etmenin tespitinde sadece ELISA ve elektron mikroskopi görüntüleri kullanıldığından, bu tespit yurtdışında kesin olmayan teyit edilmemiş kayıt olarak bildirilmektedir (Anonymous 2016b). Yürütmüş olduğumuz çalışmada ise toplanan $P$. spumarius'in söz konusu hastalık etmenini taşıyıp taşımadığına dair PCR çalışması yapılmamıştır. Akdeniz bölgesinde Auchenorrhyncha türlerinin belirlenmesinin hedeflendiği bu çalışmada, elde edilen $P$. spumarius 'un $X$. fastidiosa bakterisini taşımasına dikkat çekmede bölge zeytin üreticilerinin uyarılması hedeflenmiştir. Bu bakterinin yaygın olduğu Akdeniz iklimine sahip ülkelerdeki benzer ekolojik koşulları sağlaması nedeniyle bölge zeytin üretimi için potansiyel tehlike konumundadır. Bu hastalığın ülkemize girmesi veya tespit edilmesi durumunda, zeytin plantasyonlarını da içeren çok sayıda konukçuda muhtemel zararı belirlemek mümkün görünmemektedir. Bu nedenle bitki karantina tedbirlerine çok özen gösterilmeli, hastalığın sürekli sürveyi yapılarak takip edilmelidir. Hastalığın belirlenmesi durumunda sanitasyon çalışmalarına hızlı bir şekilde geçilmelidir. 
Zeytinlerde potansiyel tehlike: Philaenus spumarius (Linnaeus) (Cercopidae) ve Auchenorrhyncha türleri (Hemiptera)

\section{KAYNAKLAR}

Archibald R.D. and Cox J.M. 1979. New records of plant pests in New Zealand. NZ. J. Agrig. Res., 22, 201-207.

Anonim 2016. T.C. Başbakanlık Türkiye İstatistik Kurumu. http://www.tuik.gov.tr 401 (Erişim tarihi: 25.06.2017).

Anonymous 2015a. FAOSAT. http: // faostat.fao. org (Erişim tarihi: 12.11.2016).

Anonymous 2015b. Scientific Opinion: On the risk to plant health posed by Xylella fastidiosa in the EU territory, with the identification and evaluation of risk reduction options. EFSA Panel on Plant Health (PLH), EFSA Journal 2015;13(1):3989, 262p.

Anonymous 2016a. First reports of Xylella fastidiosa in the EPPO region - Special Alert.https://www.eppo.int/QUARANTINE/special topics/Xylella fastidiosa/Xylell a fastidiosa.htm (Erişim tarihi: 05.08.2017).

Anonymous 2016b. Decleration of Turkey on Xylella fastidiosa. https://www.ippc.int/static/media/files/pestreport/2016/10/06/Turkey_Decleration.p df (Erişim tarihi: 02.11.2017).

Aysan Y. 2016. Bakteriyel yaprak yanıklığı hastalığı etmeni Xylella fastidiosa. Tarlasera,, 5. sayı (Erişim tarihi: 13.05.2016).

Başpınar H. ve Uygun N. 1994. Doğu Akdeniz Bölgesi turunçgil bahçelerindeki Cicadellidae türleri, farklı yöntemlerle populasyon dalgalanmalarının saptanması, konukçuları ve Stubborn hastalığı ile ilişkileri üzerinde araştırmalar. Tr. J. of Agricultural and Forestry, 18, 9-20.

Bolu H. 2002. Güneydoğu Anadolu Bölgesi antepfıstığı alanlarındaki böcek ve akar faunası üzerinde araştırmalar. Türk. Entomol. Derg., 26 (3), 197-208.

Booth W.J. 1993. Aspects of host plant relations in Cercopidae (Homoptera: Auchenorrhyncha). Ph.D. Thesis, University of Wales, Cardiff, 1993.

Chen J., Groves R., Civerolo E. L., Viveros M., Freeman M. and Zhang Y. 2005. Two Xylella fastidiosa genotypes associated with almond leaf scorch disease on the same location in California. Phytopathology, 95, 708-714.

Daane K.M., Wistrom C.M., Shapland E.B. and Sisterson M.S. 2011. Seasonal abundance of Draeculacephala minerva and other Xylella fastidiosa vectors in California almond orchards and vineyards. J. Econ. Entomol., 104, 367-374.

Davis M.J., Purcell A.H. and Thompson S.V. 1978. Pierce's disease of grapevines: Isolation of the causal bacterium. Science, 199, 75-77.

Guldur M.E., Caglar B.K., Castellano M.A., Ulnu L., Guran S., Yilmaz M.A. and Martelli G.P. 2005. First report of almond leaf scorch in Turkey. Journal of Plant Pathology, $87,246$.

Harris K.F. 1981. Arthopod and Nematode Vectors of Plant Viruses. Ann. Rev. Phytopath., 19, 391-486. 
Harris K.F. 1983. Auchenorrhynchous vectors of plant viruses: virus-vector interactions and transmission mechanisms. In: 1 st. International workshop on leafhoppers and planthoppers of economic importance. (eds: Knight W.J., Pant N.C., Robertson T.S. and Wilson M.R.) Commonwealth Institute of Entomology, London, 405-413.

Kaplan C., Büyük M. ve Eren S. 2011. Güneydoğu Anadolu Bölgesi zeytin bahçelerinde saptanan zararlı ve faydalı böcek türleri. Bitki Koruma Bülteni, 51 (3), 267-275.

Krugner R., Sisterson M S., Chen J., Stenger D. C. and Johnson M. W. 2014. Evaluation of olive as a host of Xylella fastidiosa and associated sharpshooter vectors. Plant Dis., 98, 1186-1193.

Nault L.R. 1986. Origin and evolution of Auchenorrhyncha (Homoptera) an annotated Check List. Polish Academy of Sciences, Institute of Zoology, Polish Scientific Publishers Warszawa, 1972, $550 \mathrm{pp}$.

Öztürk N., Ulusoy M. R. ve Bayhan E. 2005. Doğu Akdeniz Bölgesi nar alanlarında saptanan zararlılar ve doğal düşman türleri. Türkiye Entomoloji Dergisi, 29 (3), 225-235.

Pala Y., Nogay A., Damgacı E. ve Altın M. 2001. Zeytin Bahçelerinde Entegre Mücadele Teknik Talimatı. Tarım ve Köyişleri Bakanlığı, Tarımsal Araştırmalar Genel Müdürlüğü, Bitki Sağlığı Araştırmaları Daire Başkanlığı, Ankara, 84 s.

Purcell A.H. and Saunders S. R. 1999. Fate of Pierce's disease strains of Xylella fastidiosa in common riparian plants in California. Plant Dis., 83, 825-830.

Saponari M., Loconsole G., Cornara D., Yokomi R.K., De Stradis A., Boscia D., Bosco D., Martelli G.P., Krugner R. and Porcelli F. 2014. Infectivity and transmission of Xylellua fastidiosa by Philaenus spumarius (Hemiptera: Aphrophoridae) in Apulia, Italy. J Econ Entomol., 107 (4), 1316-9.

Saponari M., Boscia D., Altamura G., D'Attoma G., Cavalieri V. et al. 2016. Pilot project on Xylella fastidiosa to reduce risk assessment uncertainties. EFSA supporting publication EN - 1013. 60 pp. http://onlinelibrary.wiley.com/doi/10.2903/sp.efsa.2016.EN-1013/pdf

Sisterson M.S., Thammiraju S.R., Lynn-Patterson K., Groves R.L. and Daane K. M. 2010. Epidemiology of diseases caused by Xylella fastidiosa in California: Evaluation of alfalfa as a source of vectors and inocula. Plant Dis., 94, 827-834.

Thompson V. 1998. Spittlebugs associated with actinorhizal host plants. 11th International Conference on Frankia and Actinorhizal Plants, 7-11 June, Illinois.

Weaver C.R. and King D.R. 1954. Meadow spittlebug Philaenus leucophtalmus (L.). Ohio. Agric. Exp. Stn. Res. Bull., 741, 1-99.

Yayla A. 1983. Antalya ili zeytin zararlıları ile doğal düşmanlarının tespiti üzerinde ön çalışmalar. Bit. Kor. Bült., 23 (4), 188-206

Yurtsever S. 1999. Inheritance of three dorsal colour/pattern morphs in some Turkish Philaenus spumarius (Homoptera: Cercopidae) populations. Isr. J. Zool., 45, 361-369.

Yurtsever S. 2000. On the Polymorphic Meadow Spittlebug, Philaenus spumarius (L.) (Homoptera: Cercopidae). Turk J Zool., 24, 447-459. 